\title{
Unauthorised absence from school among looked after children: perspectives from service providers
}

\begin{abstract}
In this study ten service providers who had experience of working with a young person who was both looked after by their local authority and engaged in unauthorised absence from school, participated in semi-structured, one to one interviews. Focus was placed on their individual experiences of working with looked after children who engaged in this type of behaviour, and what they found to be either helpful or unhelpful when addressing truancy. Thematic Content Analysis was conducted on the interview transcripts which revealed that their young people encountered social difficulties at school relating to their interpersonal skills, the effect of stigma and an increased need for privacy. Looked after children were described as having different priorities than their non-looked after peers associated with family contact, moving home and managing their emotional needs. Meeting support needs, reframing priorities and unhelpful responses from service providers were also identified as key areas of concern when addressing unauthorised absence.
\end{abstract}

Keywords: unauthorised absence, school, education, looked after children
Volume 9 Issue 6 - 2018

\author{
Emma O'Neill, Una O'Connor-Bones, Tony \\ Cassidy \\ Department of Psychology, Ulster University, Ireland
}

\begin{abstract}
Correspondence: Tony Cassidy, Department of Psychology, Ulster University, Ireland, Coleraine Campus, Cromore Road, Coleraine BT52 ISA, Ireland, Tel +44(0) 2870I23025,
\end{abstract} Email t.cassedy@ulster.ac.uk

Received: November 01, 2018 | Published: November 13, 2018

\section{Background}

A particular concern is the educational attainment of looked after children $^{1-3}$ with a growing body of literature detailing their under achievement as well as the longer term impact that this can have. ${ }^{4}$ A range of factors have been associated with the low educational achievement of looked after children including pre-care experiences and characteristics of looked after children which may disadvantage them educationally with higher numbers of looked after children having educational and behavioural difficulties and being excluded from school. ${ }^{5}$ Other research suggests that structural features of the care system including placement type and placement stability can greatly influence educational outcomes. It is widely recognised that children placed in foster or kinship care are more likely to have favourable outcomes in comparison to children who live in residential settings ${ }^{6}$ placement changes are disruptive and unsettling and can mean subsequently changing school. ${ }^{7}$ In addition the importance of maintaining family relationships and managing emotional/physical needs can all lower the priority status given to education by social., Why children or young people do not attend school in this way has generated a range of research which suggests that truancy can be traced to personal, academic or social difficulties, chaotic family life, unsupportive school environments and lack of community support. ${ }^{10}$ Capps ${ }^{11}$ describes truants as seeing the world around them as unstable and confusing with many coming from dysfunctional, unstable and insecure homes. Studies that have focused on the psychology of truancy indicate that anxiety is a prominent factor, with the act of refusing to go to school serving a functional purpose of enabling pupils to avoid anxiety producing situations. ${ }^{12}$ An alternative perspective is that school refusal is a normal avoidance reaction to what is perceived as an unpleasant, unsatisfying or hostile environment. Peer rejection, bullying, poor relationships with teachers / school staff, academic / educational difficulties have been reported among disengaged pupils suggesting that there is an overlap of factors concerning both the individual and those who they come into contact with as part of their educational process. If their experiences of school are difficult and stressful then pupils are less likely to feel motivated or rewarded by attending school. Engaging in unauthorised absence from school has been identified in the literature as problem behaviour among some looked after children. In doing so, these young people have a reduced opportunity to benefit from the education process that has the potential to improve their life chances. Educational achievement is a predictor of success in adulthood and those who leave with no qualifications can encounter challenges with finances and employment. Attendance rates are linked to educational outcomes so it is important to consider what can be learned from those who have difficulties attending. Researchers have sought to understand why education for looked after children is so problematic yet there is limited exploration of individual behaviours associated with school and education. This study aims to explore with professionals who support looked after children what this behaviour reveals about their experiences at school and their perceptions of education. It also aimed to identify what has been helpful or unhelpful in addressing unauthorised absence.

\section{Method}

Design: This study utilized a qualitative research methodology using semi-structured, in-depth interviews as the primary source for data collection. Participants were recruited from the Education and Library Boards and the voluntary/community sector using snowball sampling. Participants: Participants interviewed were three Educational Psychologists, one Consultant Clinical Child Psychologist, and six project workers working in the voluntary sector directly with looked after children. All participants worked with young people on a practical basis to help them navigate key areas in their lives including education and training during and beyond care. Participants were selected because they had substantial previous experience of working directly with children and young people who had engaged in unauthorised absence. All had a minimum of three years experience of working with the children or young people.

Ethics: Ethical approval was obtained from the University Research Ethics committee.

Procedure: Participants who were interested in the project were 
initially contacted by email with an information sheet and consent form attached to provide them with a full description of the research. Upon agreement to participate, arrangements were made for the researcher to meet with participants at their place of work for an interview.

Data analysis: Each interview recording was transcribed verbatim.
Thematic Content Analysis (TCA) was then conducted on each of the interview transcripts.

\section{Results}

Thematic analysis yielded six broad themes and twenty-two subthemes as shown and described in Table 1.

Table I Description of themes and sub-themes generated

\begin{tabular}{|c|c|c|}
\hline Themes & Sub-themes & Description \\
\hline $\begin{array}{l}\text { Peer } \\
\text { relations }\end{array}$ & $\begin{array}{l}\text { Lack of fit } \\
\text { Social relations } \\
\text { Stigma } \\
\text { Need for privacy } \\
\text { Emotional difficulties }\end{array}$ & $\begin{array}{l}\text { Young people were described as having persistent negative experiences with their peers while in attendance at } \\
\text { school. These include the stigma associated with being in care and the lack of privacy in relation to their personal } \\
\text { circumstances. Some young people struggled with social relationships in school and had difficulties managing their } \\
\text { emotions. The accumulation of these negative experience resulted in young people not wanting to attend because } \\
\text { they knew if they did that it would be unpleasant. }\end{array}$ \\
\hline Priorities & $\begin{array}{l}\text { Family contact } \\
\text { Moving home } \\
\text { Emotional needs } \\
\text { Reframing priorities }\end{array}$ & $\begin{array}{l}\text { Attending school was not a priority for their young people. The immediacy of their current circumstances such } \\
\text { as moving home or when they would see their family again became pre-occupying concerns. The emotional needs } \\
\text { of young people needed to take priority and in reality until these were managed effectively education cannot be a } \\
\text { priority. }\end{array}$ \\
\hline $\begin{array}{l}\text { Educational } \\
\text { context }\end{array}$ & $\begin{array}{l}\text { Vicious circle } \\
\text { Schools response } \\
\text { Negative discipline }\end{array}$ & $\begin{array}{l}\text { Many young people were described as being trapped in a vicious circle because they were not attending. By missing } \\
\text { out on class work and the likelihood of reprimand from the school, the cycle of not attending continued. The negative } \\
\text { reactions to unauthorised absence from school were not deemed helpful in addressing underlying issues, from both } \\
\text { service providers and schools. These were viewed as compounding the problem further. }\end{array}$ \\
\hline Motivation & $\begin{array}{l}\text { Valuing education } \\
\text { Role models } \\
\text { Encouragement } \\
\text { Significant others } \\
\text { Care environment }\end{array}$ & $\begin{array}{l}\text { Young people were viewed as simply not having any motivation to attend school. In part this lack of motivation was } \\
\text { as a result of the influence of biological family members who didn't value education. Furthermore for young people } \\
\text { living in residential care, it was felt that residential staff members were not focused on their education in ways that } \\
\text { would motivate them. They also recognised that significant adults taking an interest in their young people's education } \\
\text { had a motivational role. }\end{array}$ \\
\hline Lifestyle & $\begin{array}{l}\text { Sedentary } \\
\text { Hanging around } \\
\text { Negative activities }\end{array}$ & $\begin{array}{l}\text { When not in school young people were described as spending their time in unproductive ways such as sleeping during } \\
\text { the day, hanging around with others who also were not at school and for some engaging in negative activities such as } \\
\text { high risk behaviour. }\end{array}$ \\
\hline Support & $\begin{array}{l}\text { Emotional } \\
\text { Practical } \\
\text { Interest }\end{array}$ & $\begin{array}{l}\text { Young people needed consistent support to manage the emotional and academic demands that attending school } \\
\text { required. }\end{array}$ \\
\hline
\end{tabular}

\section{Theme I: Peer relations}

Lack of fit / social relations: All of the service providers suggested that social interaction at school is not a pleasant experience for young people and therefore this makes it less likely that they will want to attend.

Participant 1a: ...they don't fit easily into classrooms where there is a lot of conformity and where they don't feel particularly valued and where they tend to be viewed quite negatively where they view themselves quite negatively... and therefore don't have a very positive view of the experience...

Participant $1 \mathrm{~d}$ : ... they go into a formal institutional typesetting like education and are perhaps not succeeding very well there...there's an aggregate of experience if you like that is negative and so they're not succeeding at school...

Young people faced a range of social challenges every time they entered the school premises particularly in their social interactions with their school peers. Difficult social interaction was compounded by self-perceptions of being different because they were in care and the emotional stress placed on them because of their circumstances. The negative experiences associated with attending school may lead young people to view it as a hostile, stressful environment and not one where they feel they can flourish and succeed.

Participant 1j: ...the bottom line is would you go somewhere everyday where you feel a failure and embarrassed and knew that you didn't know what everybody else knew and knew you were being talked about and there is nobody on your side and you're asking that of the most unsupported vulnerable group in society...

The social environment presented challenges because young people struggled with social interaction, and forming relationships with their peers.

Participant 1d: ... a lot of looked after children struggle socially at school...

This often meant that when young people where at school they didn't have many friends and there was difficulties in forming relationships with others. 
Participant 1g: ...they might not always have had a huge amount of close friends at school as they didn't get on with that peer group... there's people in the class that they don't get on with...they maybe have that problem where they're not able to make good relationships or trust people...

Stigma: Some described how part of the reason that their young people struggled socially at school was due to the combined stigma associated with being a looked after child.

Participant $1 \mathrm{~d}$ : ...they also go in there with stigma...they have a number of stigma if you like they're not very well off because they haven't come from middle class very often middle class professional backgrounds but also they've been rejected or abandoned by their families...

The difficulties young people experienced lead to others viewing them negatively and different to their peers. Family background problems, emotional stress, being or becoming a looked after child, and differences in daily practicalities, may have been identified by other pupils who rejected them socially as a result.

Participant $1 \mathrm{~h}$ : ...it's very difficult for young people to have friends especially if they have that whole care background...

Need for privacy: Due to the difficulties in their personal lives privacy was very important young people. They didn't want their peers to be aware of their circumstances because it resulted in stigma.

Participant 1f: ...there's no doubt in my mind that she didn't want to tell anyone that she was living in supported accommodation...

However maintaining privacy was difficult to achieve.

Participant 1e:...I think that if you're in care or even a foster home children knew very quickly you were in care or children's home...

Emotional difficulties: Emotional difficulties among young people were seen to play a contributing role in their negative experiences of school.

Participant 1a: ...they've had damaged disturbed lives and they don't fit in easily...

The impact of pre-care and care experiences have emotional consequences that can mean managing and interacting in relationships with others in school is problematic. They may not have the skills to manage their emotions and due to their experiences, difficulties trusting others.

Participant 1d: ...they struggle for all sorts of reasons because they've missed out to some extent in the socialisation process in other words an experience in life that equips them for forming relationship eh mediating relationships and managing relationships...

Participant 1b: ...looked after children they do have attachment issues...

\section{Theme 2: Priorities}

Many participants identified that education and attending school could simply not be a priority for a lot of looked after children. It appeared that their personal circumstances distracted them at this particular point in their lives and that they were more focused on making sense of these circumstances.

Participant 1e: ...school was the least thing on their agenda ...that was really the last thing in their head...
Participant 1i: ...depending on the circumstances of the young person it depends what's really going on inside their head it depends what is going on in their life at that moment and going to school isn't a priority...

One participant described the experience of a young person that they worked with to demonstrate how the care system and corporate parenting contributed to education not being a priority.

Participant $1 \mathrm{j}$ : ...she was living in a residential unit but she thought she was going to be moving home to be with her mother again...I was literally in the room when the staff came into the room and said to the young person eh your birthday is at the weekend and just to let you know we're going to have to see about getting you moved out into the community...suddenly the rug was pulled...

Family contact: Some participants identified that young people were preoccupied with family difficulties and concerns about family contact.

Participant 1g: ... if they had other issues going on like family issues family contact that sort of thing or if they had important meetings coming up education just wasn't important to them...

Participant 1f: ... the biggest issue for her was that she didn't have a mother or father there..

Participant 1h: ...they've got all this shit at the back of their heads you know what if my mummy and daddy don't love me am I going to be able to go back home again...

Moving home: As some young people had to move to different placements whilst in care, interviewees considered this to be unhelpful in relation to attending school. Moving placement often meant that young people would have to start attending a new school.

Participant 1h: ...because they've just moved and they've had to move away to start a new school which is where it mostly comes from having to start a new school...

Participant 1a: ...they moved areas they had moved to a residential unit and also had to go to a new school and that was going to be quite difficult for them...

Emotional needs: For many young people their emotional needs took priority over the need for education and to attend school. Their circumstances had an emotional impact on their lives and coping with their emotions limited their capacity to focus on the need to go to school.

Participant 1d: ...surviving is their top priority in the situations that they find themselves...they're much more tied up with who loves me who cares about me what value do I have as a human being...

Participant 1i: ...he won't go to school he doesn't go to school just basically he is so sad and upset...he would miss a lot of school he's so down and getting washed you know the basic things that you do every morning he doesn't do them it's hard for him to do that...

Participant 1g: ... they just woke up that morning and they weren't going to go they were just feeling a bit down...

Reframing priorities: The reality was at least for some young people that their emotional needs had to take priority first to enable them to engage in education at a later stage.

Participant 1a: ... you have to reframe it for them and say now these years for you are when you learn to cope better with social 
situations and get on with people better and then after that you can look at those sorts of things...

Participant $1 \mathrm{~d}$ : ...in terms of helping them engage in education I think what they need to do is be engaged as people first of all...it's about helping them make some sense of their lives to have options and more options...

\section{Theme 3: Educational context}

Vicious circle: Many participants described their young people as being trapped in a vicious circle were they're not attending school because they find it difficult to be there, they engage in unauthorised absence which means they fall behind with their school work, if they do return to school there will be a consequence in terms of disciplinary action and they will need to catch up on missed work. These factors seem to contribute to a cycle of continued non-attendance which made returning in the future much more difficult:

Participant 1d: ...once they start missing out on education either by lack of concentration or failure to attend you know it becomes a vicious circle in a sense and catching up is so difficult...

Participant 1e: ...either way you end up in bother because you didn't want to be in school so I think it's a whole vicious circle...

An important acknowledgement was made by all service providers that by responding to young people who were not attending school in a negative way didn't help.

School response: Service providers described that when a young person didn't attend school, responding to this behaviour in a negative way did not resolve the underlying issues. Using force or threats was not a productive way of managing the situation and did not make young people any more likely to attend school.

Participant $1 \mathrm{~d}$ : .... what is unhelpful is that instant judgement...it's understandable it's instinctive and it's very human to react that way but it's not helpful so that sort of knee jerk response...

Participant $1 \mathrm{j}$ : ....threat doesn't work I think threats and being told that they have to is the main thing that doesn't really work it's carrot and stick and the stick seems to be used rather than the carrot...

Negative discipline: Some participants found that the way in which schools responded to the problem did not help to resolve it either. They described reactive responses were a young person would be disciplined often by suspension. This was not dealing with the underlying issues either and appeared to further complicate difficulties for young people.

Participant 1b: ...I think the discipline policies that schools have the excluding and suspension procedures are very much reactive strategies you wait until you do something wrong and you get a punishment for it and there doesn't seem to be proactive things where people are trying to get involved prior to things and stopping them from happening...

Participant 1g: ...you would have schools that would be a bit heavy handed maybe suspend them a bit too quickly you know for mitching...being too heavy handed from anybody's point of view would be detrimental to them...being treated too severely has that negative impact on them...

\section{Theme 4: Motivation}

Valuing education: Many of the service providers described their young people as lacking motivation to go to school. They didn't view school or education as important and as something they would need in their adult lives.

Participant 1e: ...they didn't see the relevance of why you needed to be at school to get exams, to have a job, career...

Role models: It was felt that this lack of motivation was, in part, influenced by their parents who for a variety of reasons did not value education. Many young people did not have role models who had engaged in education meaning that the adults in their lives weren't motivated by education and therefore couldn't motivate their young people.

Participant 1i: ...some of the young people who are living at home with their parents with the shared caring through the Trust and at home obviously for parenting reasons there wouldn't be a good push from home for parents to push them to get up in the morning or to give them that motivation to get up and ready and have their uniform sitting ready different things like that...

Participant 1g: ...it's kind of part of the family none of them really attended school and they weren't really encouraged by their carer...

Participant 1e: ...their parents weren't in a position to provide them or even wanted to stimulate them in any way around their education...

Encouragement: Some participants were critical of staff members in residential units who they felt were more orientated to dealing with the daily practicalities of looking after young people.

Participant 1a: ...I find children's homes they want children to be at school because it gets them out of the way during the day but they don't have a great interest or respect for the children being educated...so they're not so worried about the education so much as they're worried about getting them away for the day...

Participant 1e: ...staff could have been more responsible around homework but children didn't weren 't pushed inspired or encouraged...

Participant 1b: ....they're more worried about the looking after...

The care environment that young people lived in was identified as having an influential role on their behaviour.

Participant 1a: ...there is a difference between children in residential care and children in foster care that might also be due to the nature of the children those children in residential units might be harder to place in foster care and therefore more likely to refuse to attend school...

Significant others: For young people living in residential care, the behaviours of their peers were thought to have an influence. If a young person saw that another young person wasn't going to school, this led them to question if they had to go and subsequently not attend either.

Participant 1g: ...it would have been they would've copied each other so if one person didn't go to school the other person didn't go to school so it could have been a bit of copying behaviour...

Participant 1i: ...in children's homes if one young person doesn't go to school it's sort of like a domino effect that's a big experience that I've seen...

Care environment: Foster care seemed to offer a less chaotic environment and one were young people felt valued.

Participant 1g: ...the foster placement there's less children there as well and they're at different ages and different behaviours 
there's natural children there as well and it's more kind of nurturing surroundings...

Participant 1b: ...if they're in a more stable environment things are settled...

\section{Theme 5: Lifestyle}

Sedentary: If young people were attending school this would account for a large percentage of their time, however through not attending young people had to find other ways of passing their day.

Participant 1d: ...they're usually not engaged in highly productive activities..

For some young people who weren't going to school, sleeping or staying in bed during the day time seemed to be one way of passing time.

Participant 1i: ...they'd be in bed all day or most of the day sleeping...

Participant 1f: ... sleeping that would be the case in my experience.. during the day when they're not going to school they're sleeping...

Hanging around: Most participants described their young people as hanging around during the school day which meant that they weren't really doing anything other than passing time.

Participant 1d: ... they're hanging around street corners and they usually don't go to libraries to read books they usually are hanging about with other kids who are also engaged in unauthorised absences...

Participant 1i: ...around the house doing nothing or out in the streets with their friends about the town you know just doing anything but going to school...

Negative activities: Some participants described their young people as passing their day by engaging in activities that placed them at physical risk and could include criminal behaviour, alcohol and substance abuse, self- harm or sexual activity.

Participant 1h: ...they'd be drunk or they'd be found by the police were out shop lifting or they were doing things that they shouldn't be doing like breaking into places..

Participant 1c: ...shoplifting...

Participant 1e: ...messing around messing around could have been getting themselves into situations where they're out drinking they're having sex for some they're out stealing for others it was all self-destruct really...some of them would've sat and self-harmed or would've sniffed and got really high..

\section{Theme 6: Support}

All service providers described the importance of individualised support for their young people in all aspects of their lives.

Emotional: There was a strong need for emotional support for young people that involved understanding the challenges they faced in relation to school.

Participant 1g: ... a lot of praise a lot of support...recognising that they're going recognising that it's not always their top priority too that kind of thing supporting them encouraging them letting them know that you understand letting them know that you know it's not their top priority...
Participant 1i: ...raising young people's self-esteem confidence has been a good intervention with the young people in my experience...

Participant 1e: ...when people were giving them some kind of praise it worked well for them...

Practical: It was suggested that support measures put in place regarding attending school were helpful.

Participant 1j: ...some extra support if they're going back into school where they academically might have missed so some sort of support to bridge that lack of knowledge...some sort of familiarisation process of going back into school can help like you're inducted into a new job some sort of induction process schools having maybe somebody...visits just like a younger child going to school they meet the teacher before they start...

Interest: By taking an interest, service providers were actively seeking to motivate young people.

Participant 1i: ...just by having that one minute thirty second conversation well did you go to school every day this week just having that conversation encourages them and motivates them to go...

Participant 1h: ...if I was a young person I would want to be asked how your day was at school did you have a good day...saying things like well what homework have you..

\section{Discussion}

Failure to engage in education among children and young people in care has attracted political attention and policies to tackle the problem but has failed to engage in investigating the causes. Political interest and initiative is often driven more by the need to ensure these children and young people conform to the legal requirements of attendance rather than by a concern to raise their educational attainment. There is a need to really understand why so many looked after children avoid school when they can and end up with poorer outcomes than their non-looked after peers. The current study aimed to explore the issue with professionals who have experience of working with children who have engaged in unauthorised absence. Engagement in unauthorised absence from school among the young people, as described by the participants in this study, is not simply about undesirable behaviour. While this behaviour is undesirable because of the associated risks, it reveals a considerable amount of insight into their lives and is in effect an expression of the unhappiness they feel in the school and home environment.

The key findings in the study fall under six broad themes and twenty-three subthemes as shown in Table 1. These themes and subthemes are not in any order of importance, are likely to overlap and are certainly inter-related. The themes indicate that these children experience negative relations with peers based around how they are perceived, and how they perceive themselves as square pegs in round holes. It is perceived that there is a stigma attached to their identity as looked after children, which makes them stand out and become targets of negative attention from their peers. Attending school presents pupils with a platform where they develop not only academic skills, but also social skills. School is therefore a crucial testing ground for social interaction competences that typically follow a pupil throughout their life. For a young person who is living within the care system, social interactions are often negatively impacted because their circumstances present special barriers. This perpetuates their desire to avoid school. Typically, pupils who experience peer rejection in the classroom also demonstrate higher incidences of disengagement 
and behaviour problems such as negative attitudes towards school and school avoidance. Peer rejection has been found to be a strong predictor of pupils' readiness to learn and achievement motivation. ${ }^{13}$ Furthermore, pupils who are harassed by their peers are also more likely to avoid the contexts in which the harassment or rejection occurs through school avoidance. This would seem to be the case for looked after young people, who by engaging in unauthorised absence from school, are actually seeking to avoid the distressing environment that school presents. Avoidance behaviours are intended to reduce the likelihood of negative outcomes however it is well documented that avoidance of anxiety inducing situations often maintains the original anxiety. ${ }^{14}$

The stigma of being 'looked after' is one barrier that this group of young people face in social contexts and one that appears to be of significance in the school setting. Having a 'looked after' status can often be perceived by others as problem children or as at risk of offending behaviour, ${ }^{15}$ and there is rarely publicity that portrays care experienced young people in a more favourable manner. ${ }^{16}$ Stigma is a phenomenon which has a substantial impact on those targeted by it who are usually viewed by others to possess an attribute or have an association with something that is deemed unfavourable. Stigmatisation occurs when labels, negative stereotyping, discrimination and exclusion are applied in power situations that enable these opinions or behaviours to be expressed. ${ }^{17}$ Studies have shown that individuals affected by stigma have increased levels of mental health problems, poorer physical health, educational underachievement, and low socioeconomic status alongside reduced access to adequate housing and employment opportunities. ${ }^{18}$

Looked after young people often describe a need for privacy in relation to their personal circumstances, ${ }^{19}$ which is difficult to maintain when stigma or stereotypes exist among others. The reality is that for children in care the daily structure of their lives are different, often with a range of adults involved in their care and changes in living arrangements. Even the most basic discussions among peers can reveal more information than a looked after child may want others to know, contributing to challenges in social contexts of trying to maintain privacy but also develop friendships with peers. Martin \& Jackson $^{20}$ found that in a group of care leavers who had succeeded in education, 'being like other people' was important in relation to school life. These individuals emphasised that they wanted to be viewed as the same as others and not as being different or unusual.

The life circumstances of these children are such that education and school attendance is a low priority. It competes with issues around contact with their family, instability in their placements involving regular and unpredictable moves, a need to deal with their emotional life and resolve emotional difficulties, which culminates in a need for educators and other professional to reframe their perception of the child's priorities. Much educational literature is based on an implicit assumption that education is perhaps the most important aspect of a child's life. However, this study very clearly highlights the fact that education and school is not a priority for many looked after young people. In hindsight this should be obvious given the basic needs that many of these children are denied. Moving home and changes of residential placement have long been recognised as a problematic feature of the care system that does little to increase the needed stability and security for young people in care. The initial move from the family home into a care placement can be a traumatic experience for many children and as described by one participant in this study, placement changes can be sudden and often unanticipated by the young person. Moving home as an adult is recognised as being highly stressful even when it is desired, yet for these young people moving home can become a common occurrence that is often accompanied by huge emotional distress due to the uncertainty of their living arrangements and the breakdown of their previous placement. ${ }^{21}$ These children miss out on teaching and assessment for which they are reprimanded by school authorities thus forming a vicious circle which reinforces their unwillingness and even fear of attending school. Within this vicious circle a commonly used punishment is to expel or exclude children from the school which clearly is inappropriate for children who lack a desire to attend in the first place. Underlying all this is the issue of motivation. It is a fundamental attribution error ${ }^{22}$ to assume that a lack of motivation resides in the looked after child. It is a description rather than an explanation to say that a child is not interested or motivated. To address explanation one needs to ask why the child is not motivated. This study shows the complexity of looked after children's lack of motivation, which is engendered by a lack of value placed on education in their social context. Their families often do not see education as important perhaps reflecting their own low level of educational attainment. Staff in care setting may also place a limited value on education reflecting low levels of expectation for these children combined with more pressing concerns around placement and physical needs. Questions have been raised about the inadequate education and training of staff members themselves ${ }^{20}$ and previous authors have recommended that in order to improve the educational chances of these young people, a qualified and supported workforce is essential. ${ }^{23}$

School disciplinary actions are more likely to pertain to pupils with the greatest academic, emotional, social and economic needs. ${ }^{24}$ Children in the care of local authorities are more likely to be suspended or excluded from school ${ }^{25}$ yet these punishments do little to address the underlying issues that these young people present with. Nogeura ${ }^{26}$ points out that schools are more likely to react to negative behaviours while failing to address the factors that are contributing to these behaviours and by doing so further marginalise pupils further. Being trapped in a vicious circle of behaviour highlights the need for sensitive management of unauthorised absence from school by school and care authorities, so that they don't in effect create an environment of additional barriers for these young people to continue not attending. Looked after children will rarely be exposed to positive role-models among their peers, something which has been long recognised as a major influence on children's aspirations. ${ }^{20}$ One of the key factors in predicting children's educational attainment is the level of education of their mother ${ }^{27-44}$ an effect generally attributed to providing a positive role model. When children do not attend school they are faced with a life space which also needs to be understood. It seems from the data herein that much of the time out of school is spent in a sedentary way, sleeping late and hanging around with peers who are in a similar situation. These children engage in a lifestyle which is unhealthy and vulnerable to exploitation as is widely evidence in media reports of child sexual abuse. This sedentary life is not necessarily seen as a happy one and is really seen as time to be filled while avoiding school. The bottom line is that these children need consistent support to deal with their emotional difficulties, to address their life priorities, and to deal with the practical challenges set within the educational environment.

\section{Acknowledgements}

None.

\section{Conflict of interest}

The author declares that there is no conflict of interest. 


\section{References}

1. Jackson S. The education of Children in Care. Bristol Papers in Applied Social Studies No. 1. Bristol: University of Bristol; 1987.

2. Jackson S. Educating children in residential and foster care: An overview. Oxford Review of Education. 1994;20(3):267-280.

3. Sebba J, Berridge D, Luke N, et al. The Educational Progress of Looked After Children in England: Linking Care and Educational Data. Nuffield Foundation. 2015

4. McClung M, Gayle V. Exploring the care effects of multiple factors on the educational achievement of children looked after at home and away from home: an investigation of two Scottish local authorities. Child and Family Social Work. 2010;15(4):409-431.

5. Harker RM, Dobel-Ober D, Lawrence J, et al. Who Takes Care of Education? Looked after children's perceptions of support for educational progress. Child and Family Social Work. 2003;8(2):89-100.

6. Biehal N, Ellison S, Baker C, et al. Belonging and Permanence: Outcomes in Long-Term Foster Care and Adoption. The British Journal of Social Work. 2010;41(1):809-811.

7. Boddy J. Understanding permanence for looked after children: a review of research for the Care Inquiry. 2013.

8. Maxwell D, Sodha S, Stanley K. An asset account for looked after children. London: Institute for Public Policy Research; 2006.

9. Berridge D. Theory and explanation in child welfare: education and looked-after children. Child and Family Social Work. 2007;12(1):1-10.

10. McCray ED. It's 10am: Do you know where your children are? The persisting issue of school truancy. Intervention in School and Clinic. 2006;42(1):30-33.

11. Capps WR. The new face of truancy. School Administrator. 2003;60(4):34.

12. McKinney S. Truancy: A research brief. New York, NY: Vera Institute of Justice, Status Offense Resource Centre. 2013.

13. Buhs ES, Ladd GW, Herald SL. Peer exclusion and victimization: Processes that mediate the relation between peer group rejection and children's classroom engagement and achievement? Journal of Educational Psychology. 2006;98(1):1-13.

14. Gangemi A, Mancini F, Van Den Hout M. Behaviour as information: 'If I avoid then there must be a danger'. Journal of Behaviour Therapy and Experimental Psychiatry. 2012;43:1032-1038.

15. Garret MP. Mapping Child Care Social Work in the Final Years of the Twentieth Century: A Critical Response to the 'Looking After Children' System. British Journal of Social Work. 1999;29(1):27-47.

16. Hunt J, Waterhouse S, Lutman E. Keeping them in the family: Outcomes for abused and neglected children placed with family or friends carers though care proceedings, London: Department of Children, Schools and Families. 2008

17. Major B, O’Brien LT. The Social Psychology of Stigma. Annual Review of Psychology. 2005;56:393-421.

18. Yinger JM. Ethnicity: Source of Strength? Source of Conflict? New York: New York Press; 1994.

19. Munro E. Empowering looked after children. London: LSE Research Articles Online. 2001

20. Martin PY, Jackson S. Educational success for children in public care: advice from a group of high achievers. Child and Family Social Work. 2002;7(2):121-130

21. O'Sullivan A, Westerman R. Closing the Gap: Investigating the Barriers to Educational Achievement for Looked After Children. Adoption and Fostering. 2007;31(1):13-22.
22. Jones EE, Harris VA. The attribution of attitudes. Journal of Experimental Social Psychology. 1967;3(1):1-24.

23. Gallagher B, Brannan C, Jones R, et al. Good practice in the education of children in residential care. British Journal of Social Work. 2004;34(8):1133-1160.

24. Johnson T, Boyden JE, Pittz W. Racial profiling and punishment in U.S. public schools: How zero tolerance policies and high stakes testing subvert academic excellence and racial equity. Oakland, CA: Applied Research Centre; 2001.

25. Francis JR. A Framework for Understanding and Researching Audit Quality. Journal of Practice \& Theory. 2011; 30(2):125-152.

26. Nogeura, PA. Schools, Prisons, and Social Implications of Punishment: Rethinking Disciplinary Practices. Theory into Practise. 2003;42(4):341-350.

27. Magnuson K. Maternal education and children's academic achievement during middle childhood. Developmental Psychology. 2007;43(6):1497-1512.

28. Anderson JA, Baym G. Philosophies and Philosophic Issues in Communication. Journal of Communication. 2004;54(1):589-615.

29. Berridge D, Biehal N, Henry L. Living in children's residential homes London: Department for Education. 2011.

30. Biehal N. Reuniting Children with their Families: Reconsidering the Evidence on Timing, Contact and Outcomes. The British Journal of Social Work. 2007;37(5):807-882.

31. Boyatzis RE. Transforming Qualitative Information: Thematic Analysis and Code Development. London: Sage. 1998

32. Braun V, Clarke V. Using thematic analysis in psychology. Qualitative Research in Psychology. 2006;3(2):77-101.

33. Chamberlain P, Moore K. Models of community treatment for serious juvenile offenders. Social programs that really work. 1998;258-276.

34. Emond, R. Putting the Care into Residential Care: The Role of Young People. Journal of Social Work. 2003;3(3):321-337.

35. Happer, Helen, McCreadie et al. Celebrating Success: What Helps Looked After Children Succeed. Edinburgh, UK: Social Work Inspection Agency. 2006

36. Hartup WW. Social Relationships and their Emotional Significance. American Psychologist. 1989;44(2):120-126

37. Jacobsen T, Hofmann V. Children's attachment representations: Longitudinal relations to school behavior and academic competency in middle childhood and adolescence. Dev Psychol. 1997;33(4):703-710.

38. Ladd GW. Peer Relationships and Social Competence during Early and Middle Childhood. Annual Review of Psychology. 1999;50:333-359.

39. Lazarus R, Folkman S. Stress, appraisal, and coping. New York: Springer; 1984.

40. Lazarus RS. Emotion and adaptation. London: Oxford University Press 1991.

41. Macaskill C. Safe Contact - Children in permanent placement and contact with their birth relatives. Dorset: Russell House Publishing; 2002.

42. O’Conner E, McCartney K. Testing associations between young children's relationships with mothers and teachers. Journal of Educational Psychology. 2006;98(1):87-98.

43. Sinclair I. Fostering Now: Messages from Research. London: Jessica Kingsley; 2005.

44. Smith JA. Qualitative Psychology: A Practical Guide to Research Methods. London: Sage Publications; 2003. 